\title{
Molecular mechanism of silver nanoparticles in human intestinal cells
}

Linda Böhmert ${ }^{1, *}$, Birgit Niemann ${ }^{1}$, Dajana Lichtenstein ${ }^{1}$, Sabine Juling $^{1}$, Alfonso Lampen ${ }^{1}$

${ }^{1}$ BfR Federal Institute for Risk Assessment, Max-Dohrn-Str. 8-10, 10589 Berlin, Germany 

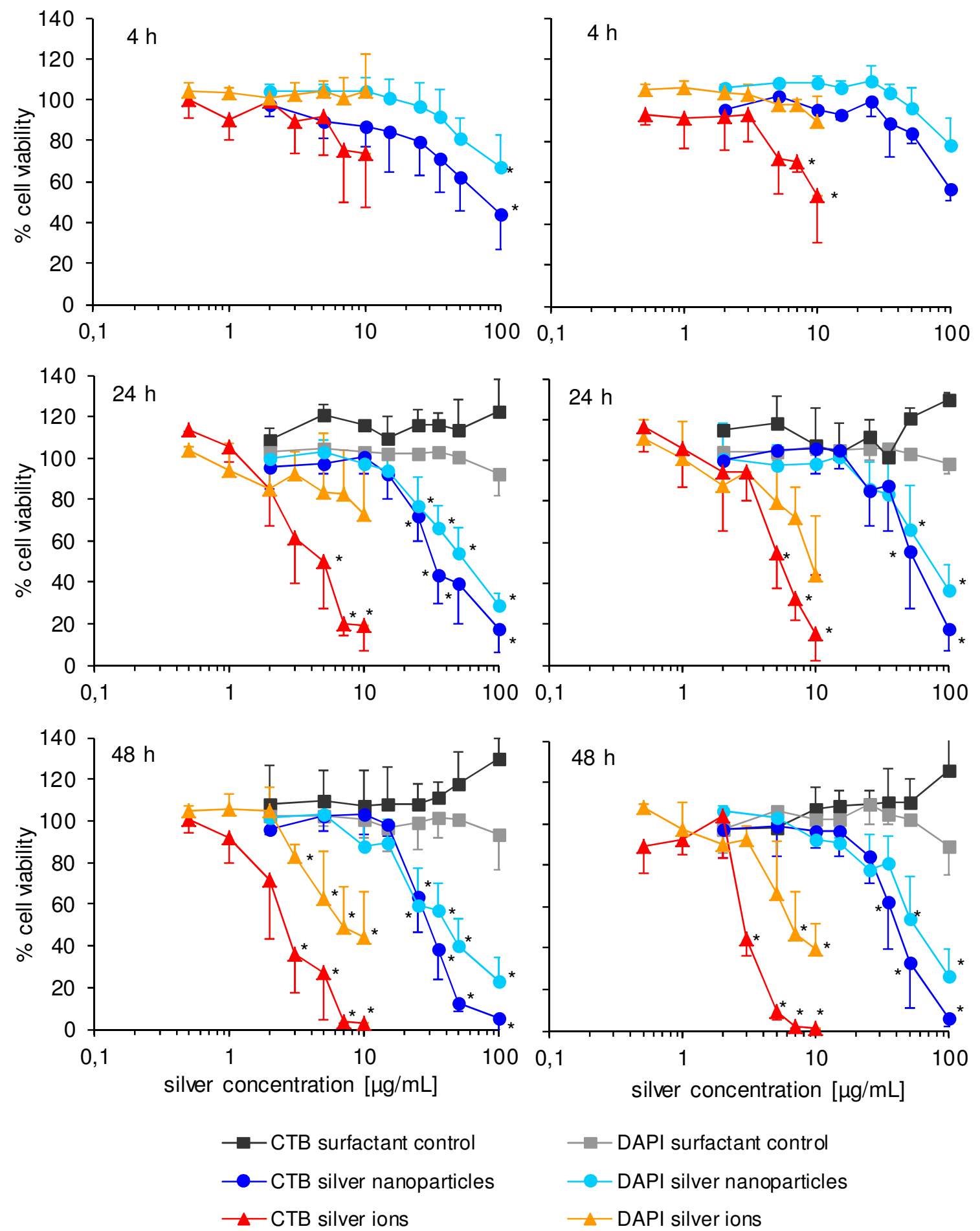

Figure S 1: Results of the CTB assays to assess cell viabilities and of DAPI staining to assess the cell number of differentiated Caco-2 cells after incubation with surfactant control, surfactant coated silver nanoparticles, and silver ions for 4, 24 and 48 h. 10000 Caco-2 cells per well were seeded into 96 well plates and differentiated for 21 days. They were incubated in $300 \mu \mathrm{L}$. Medium control was set to $100 \%$. The experiment was reproduced three times. Asterisks (*) mark significant differences, as compared to the medium control (Student's $\mathrm{t}$ test $\mathrm{p} \leq 0.05$ ). 

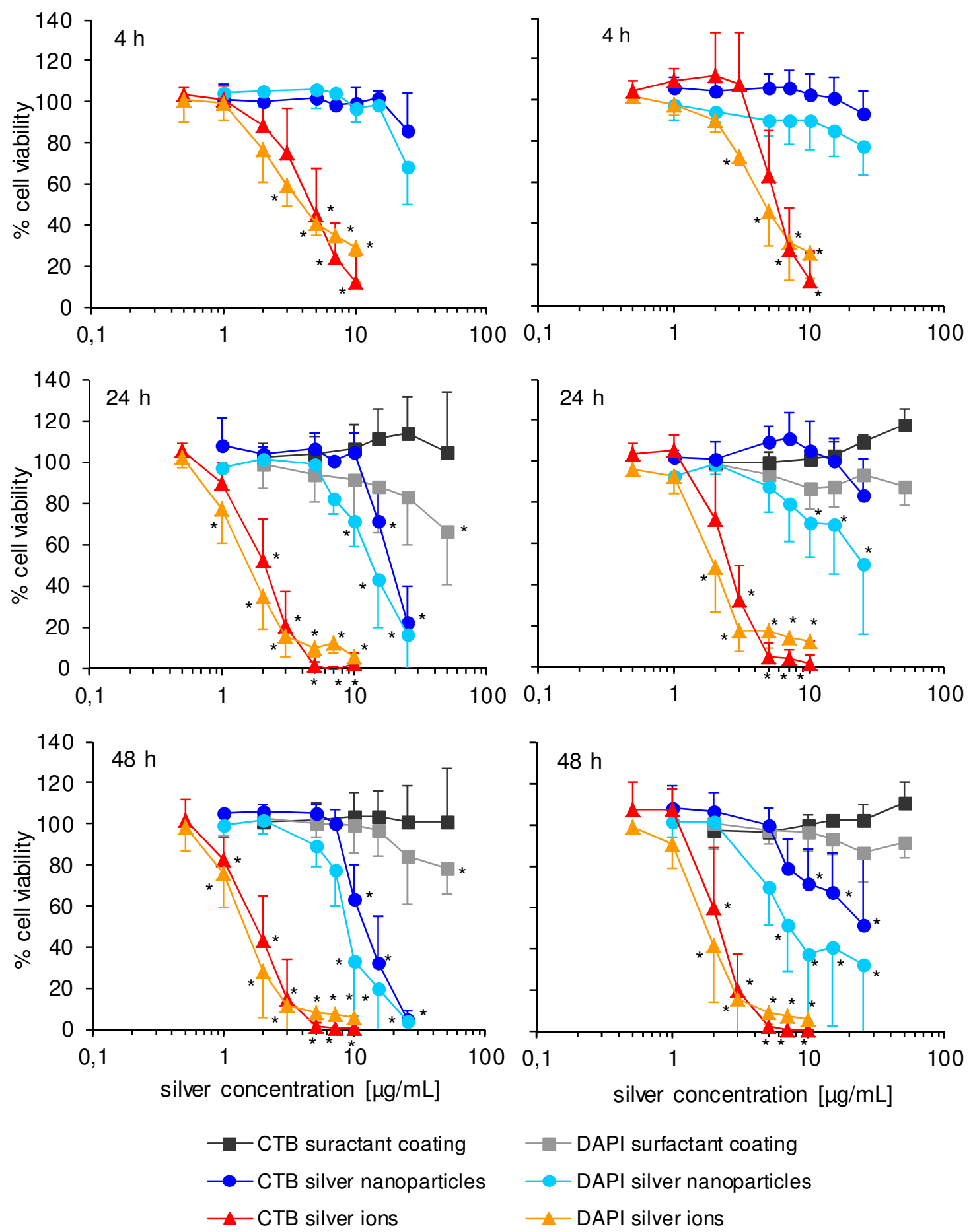

Figure S 2: Results of the CTB assays to assess cell viabilities and DAPI staining to assess the cell number of proliferating Caco-2 cells after incubation with surfactant control, surfactant coated silver nanoparticles, or silver ion for 4, 24 and 48 h. 10000 Caco- 2 cells per well were seeded into 96 well plates and cultivated for $24 \mathrm{~h}$ in $100 \mu \mathrm{L}$ medium. Medium control was set to $100 \%$. The experiment was reproduced three times. Asterisks $\left(^{*}\right)$ mark significant differences compared to the medium control (Student's t test $\mathrm{p} \leq 0.05$ ). 

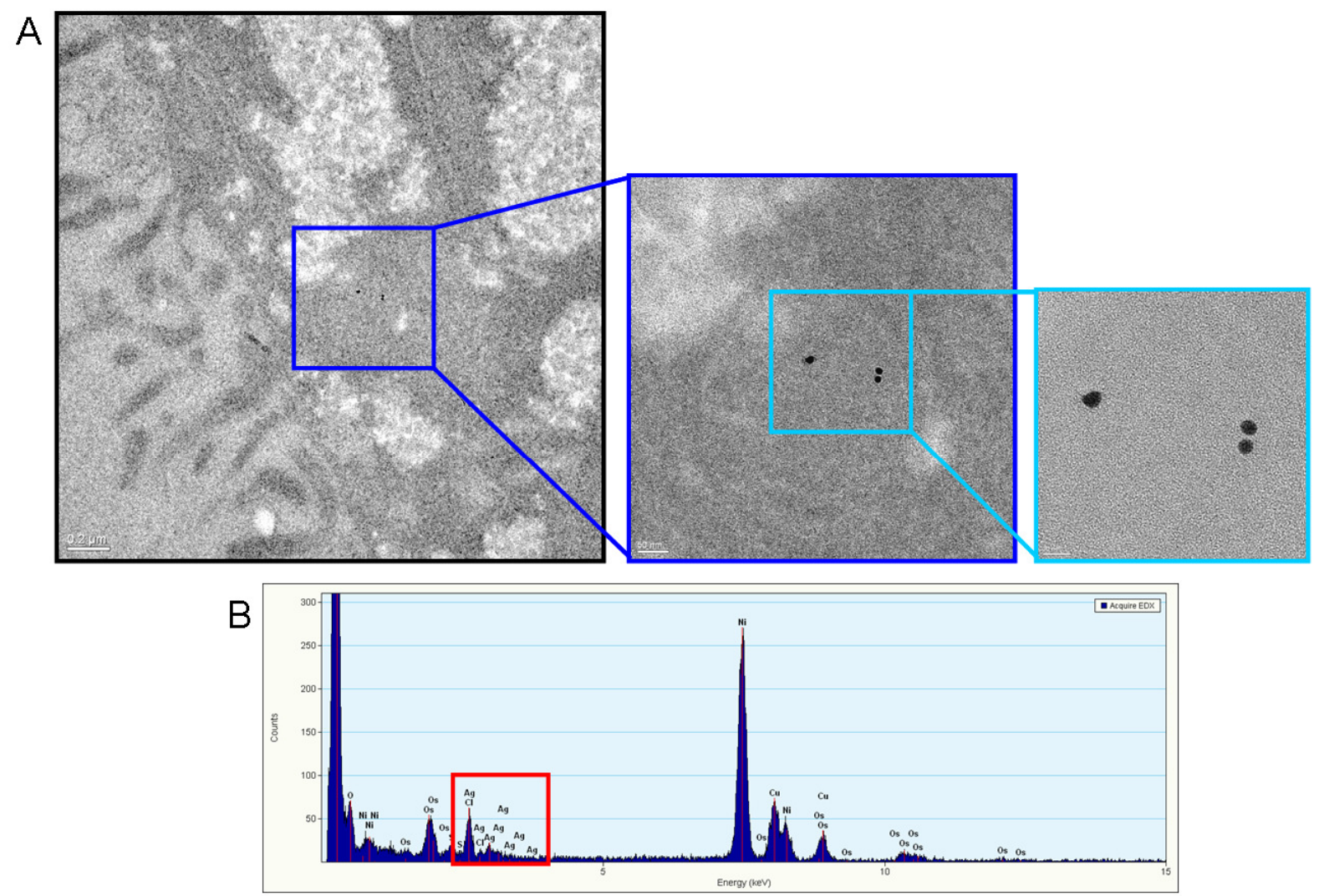

Figure S 3: (A) Transmission electron microscopic (TEM) pictures and (B) energy dispersive X-ray (EDX) analysis of differentiated Caco-2 cells. Cells were grown on transwell inserts. Fully differentiated cells were exposed to $20 \mu \mathrm{g} / \mathrm{mL}$ surfactant coated silver nanoparticles for $24 \mathrm{~h}$. Afterwards, cells were fixed and analyzed by TEM and EDX. The EDX analysis shows a representative spectrum of sample regions where nanoparticles are located. Red square indicates the silver signal.
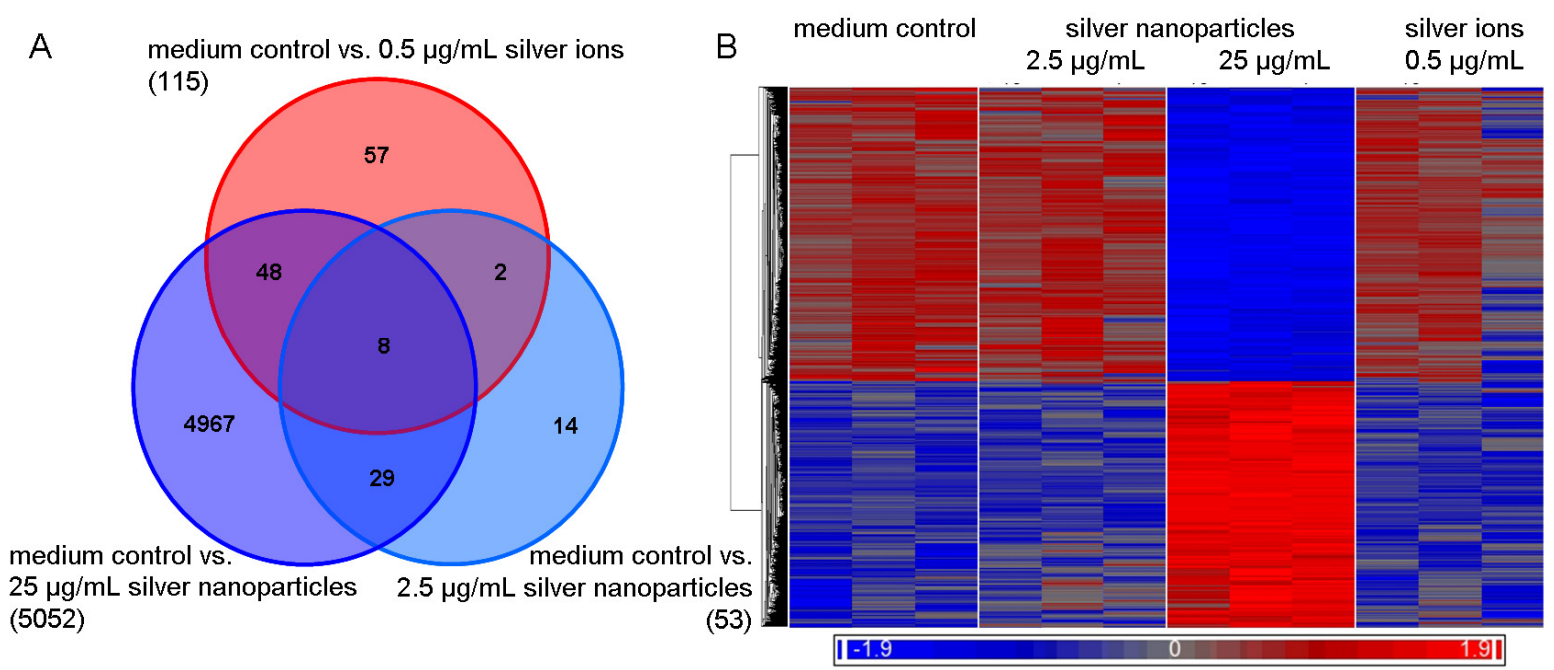

Figure S 4: (A) Venn diagram and (B) heat map of genes that are regulated in differentiated Caco-2 cells after $24 \mathrm{~h}$ treatment with silver nanoparticles and silver ions. All genes are significantly $(\mathrm{p}<0.05)$ and at least $+/-1.4$ fold regulated, as compared to the medium control. 


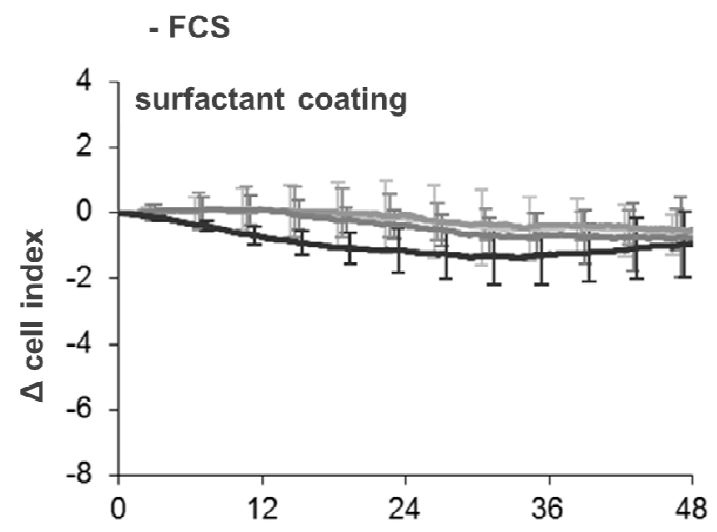

+ FCS
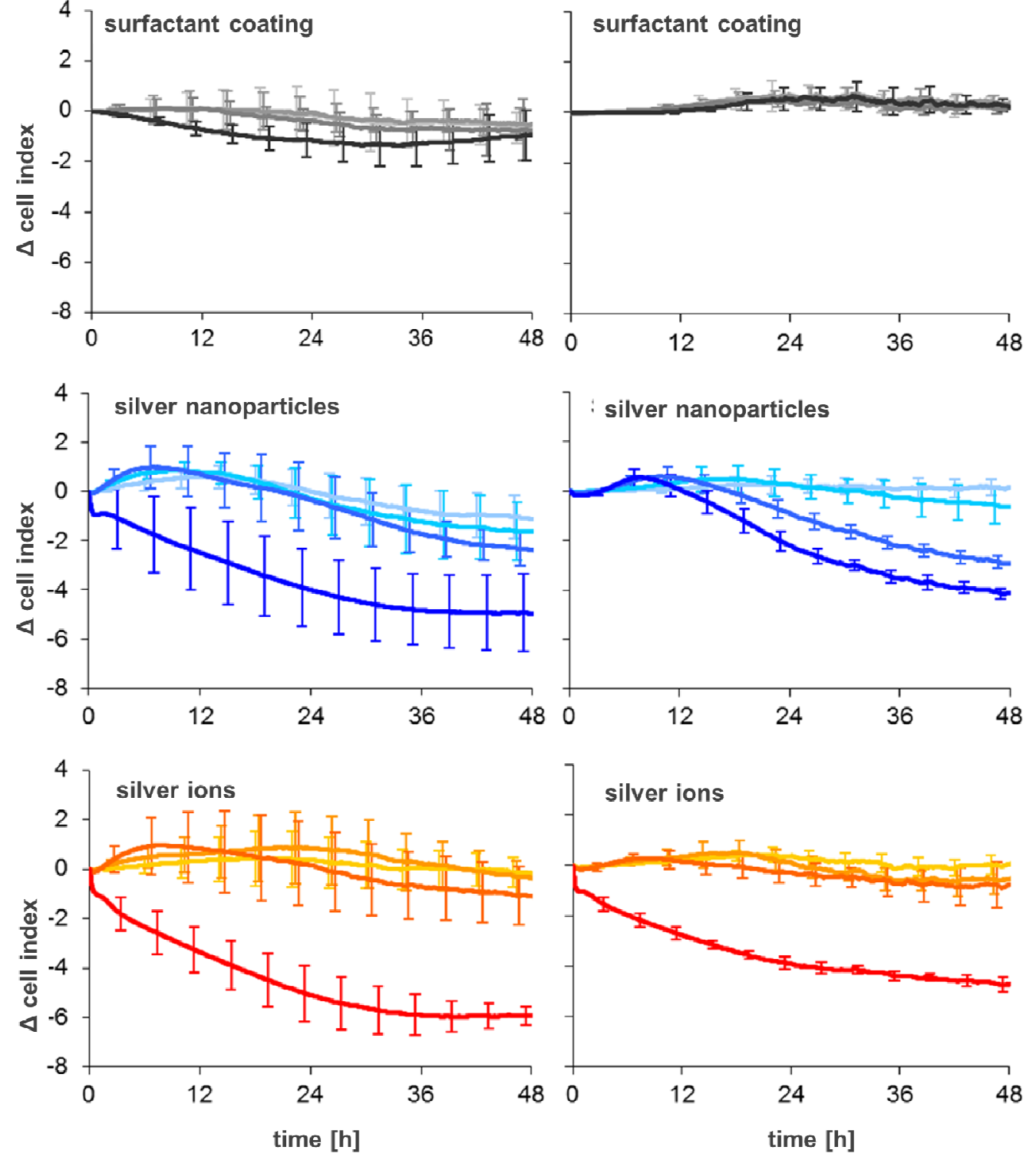

\begin{tabular}{|c|c|c|c|c|}
\hline surfactant coating & $2 \mu \mathrm{g} / \mathrm{mL}$ & $5 \mu \mathrm{g} / \mathrm{mL}$ & $=10 \mu \mathrm{g} / \mathrm{mL}$ & $=25 \mu \mathrm{g} / \mathrm{mL}$ \\
\hline silver nanoparticles & $2 \mu \mathrm{g} / \mathrm{mL}$ & - $5 \mu \mathrm{g} / \mathrm{mL}$ & - $10 \mu \mathrm{g} / \mathrm{mL}$ & - $25 \mu \mathrm{g} / \mathrm{mL}$ \\
\hline silver ions & $\triangle 0,25 \mu \mathrm{g} / \mathrm{mL}$ & $\Delta 0,5 \mu \mathrm{g} / \mathrm{mL}$ & $\Delta 1 \mu \mathrm{g} / \mathrm{mL}$ & $\Delta 5 \mu \mathrm{g} / \mathrm{mL}$ \\
\hline
\end{tabular}

Figure S 5: The xCELLigence impedance measurements are shown for proliferating Caco-2 cells. $\Delta$ cell index is plotted as a measure of impedance-based time-dependent cell response of Caco-2 cells to the exposure to surfactant control, surfactant coated silver nanoparticles, or silver ions for up to 48 h. 6,125 Caco- 2 cell per well (corresponding 10000 cell per well of a 96 well plate) were seeded into E-plates and grown for $24 \mathrm{~h}$. Then, they were incubated with medium control, surfactant control, silver ions, or silver nanoparticles $(100 \mu \mathrm{L})$ and monitored for $48 \mathrm{~h}$. The medium control and the time of incubation were set to 0 cell index. The experiment was reproduced two times. 

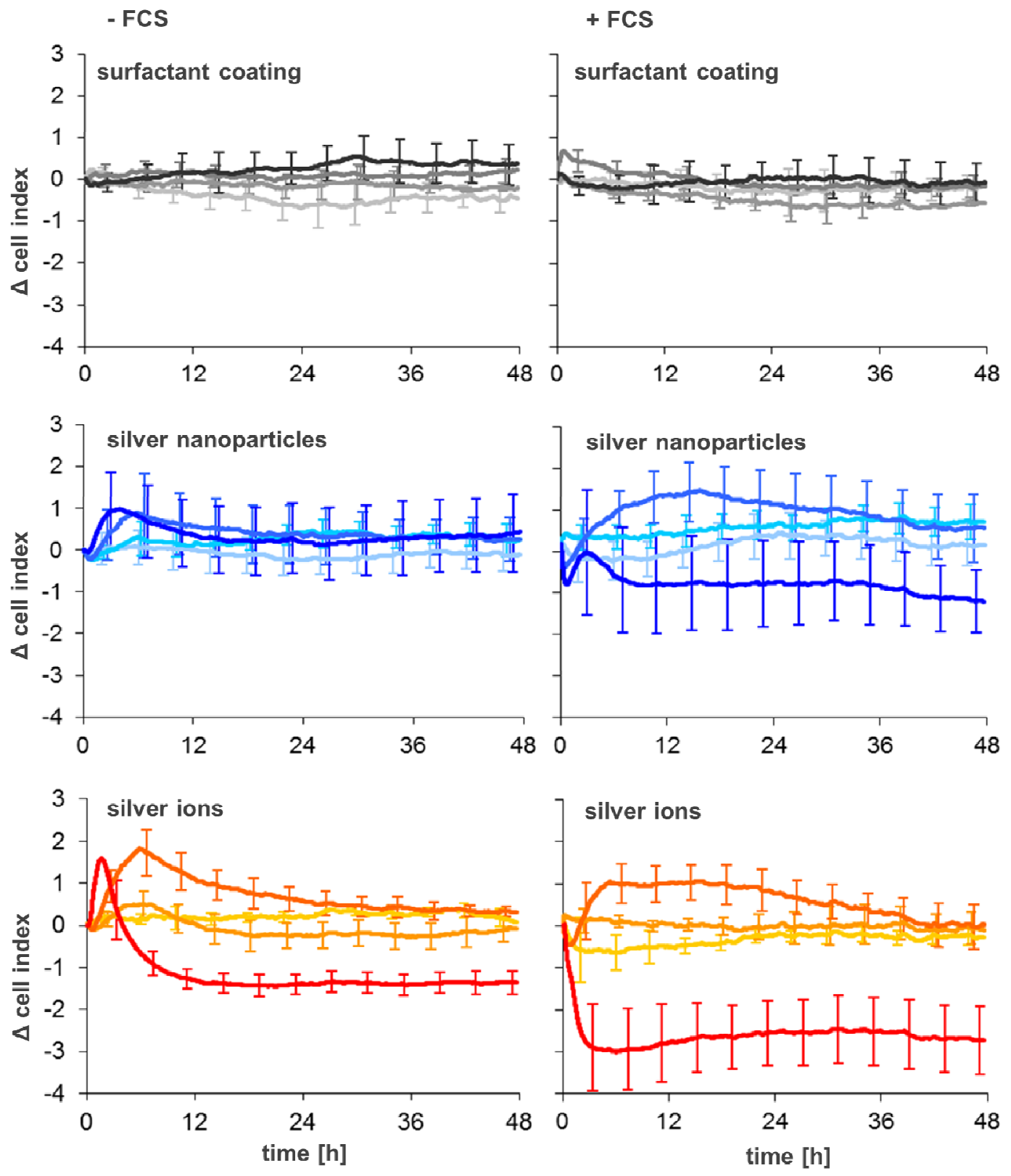

\begin{tabular}{l|cccc}
\cline { 2 - 4 } surfactant coating & $\square \mu \mathrm{g} / \mathrm{mL}$ & $-10 \mu / \mathrm{mL}$ & $-25 \mu \mathrm{g} / \mathrm{mL}$ & $\square 50 \mu \mathrm{g} / \mathrm{mL}$ \\
silver nanoparticles & $5 \mu \mathrm{g} / \mathrm{mL}$ & $\bullet 10 \mu \mathrm{g} / \mathrm{mL}$ & $\bullet 25 \mu \mathrm{g} / \mathrm{mL}$ & $\bullet 50 \mu \mathrm{g} / \mathrm{mL}$ \\
silver ions & $\Delta 0,5 \mu \mathrm{g} / \mathrm{mL}$ & $\Delta 1 \mu \mathrm{g} / \mathrm{mL}$ & $\Delta 2 \mu \mathrm{g} / \mathrm{mL}$ & $\Delta 10 \mu \mathrm{g} / \mathrm{mL}$ \\
\hline
\end{tabular}

Figure S 6: The xCELLigence impedance measurements are shown for differentiated Caco-2 cells. $\Delta$ cell index is plotted as a measure of impedance-based time-dependent cell response of Caco-2 cells to the exposure to surfactant control, surfactant coated silver nanoparticles and silver ions up to 48 h. 6125 Caco-2 cell per well (corresponding 10000 cell per well of a 96 well plate) were seeded into E-plates and differentiated for 21 days. Then, they were incubated with medium control, surfactant control, silver ions and silver nanoparticles $(100 \mu \mathrm{L})$ and monitored for $48 \mathrm{~h}$. The medium control and the time of incubation were set to 0 cell index. The experiment was reproduced two times. 

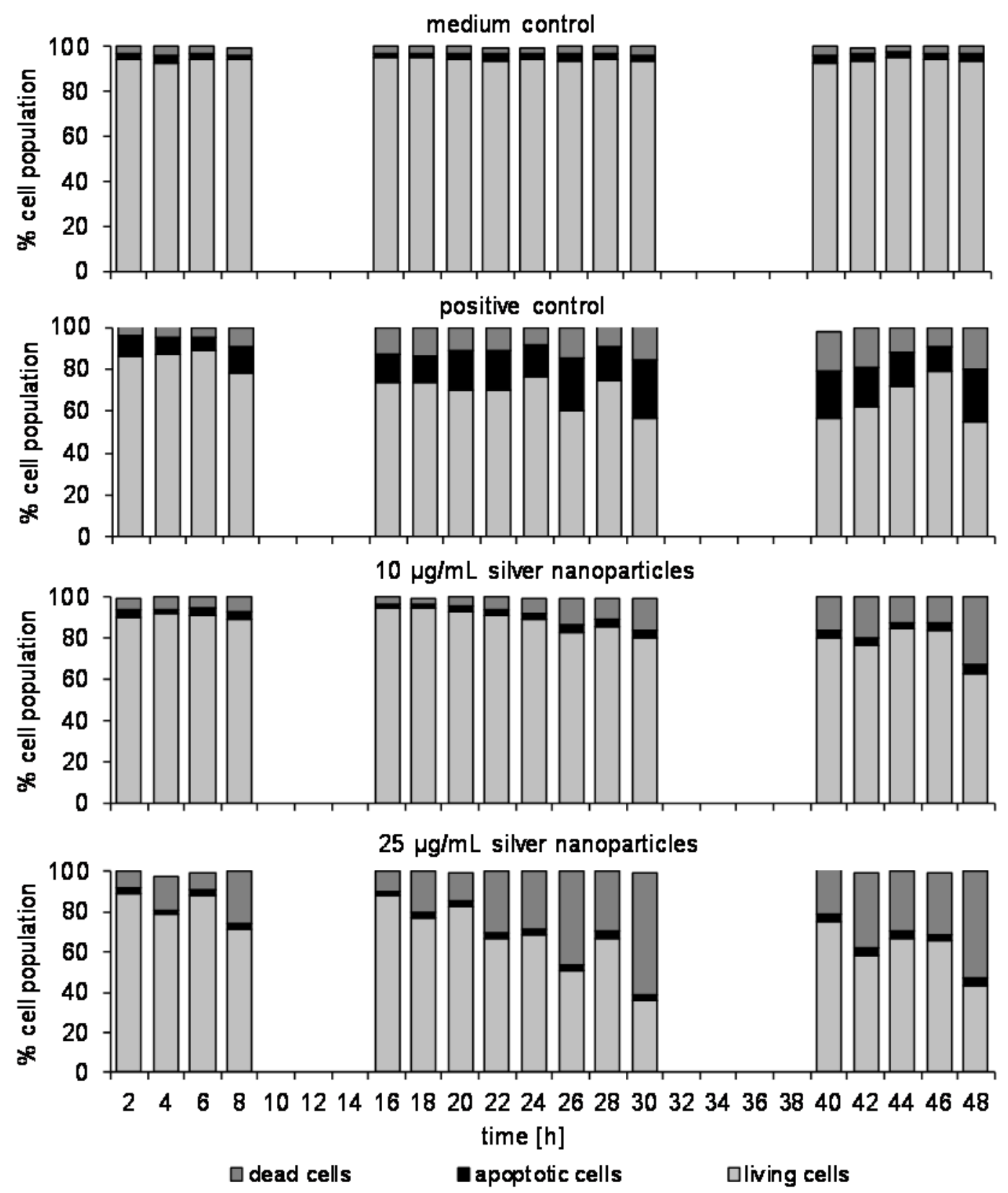

Figure S 7: Annexin V/AAD staining of proliferating Caco-2 cells in serum free cell culture medium after incubation with silver nanoparticles. 100,000 Caco-2 cells per well were seeded into 12 well plates, cultivated for $24 \mathrm{~h}$ and incubated. Staurosporine $(10 \mu \mathrm{M})$ was used as a positive control. Afterwards, cells were harvested, stained and measured using FACS analysis analyzing 10000 cells per treatment. The experiment was reproduced two times. The figure shows the average for all experiments. 


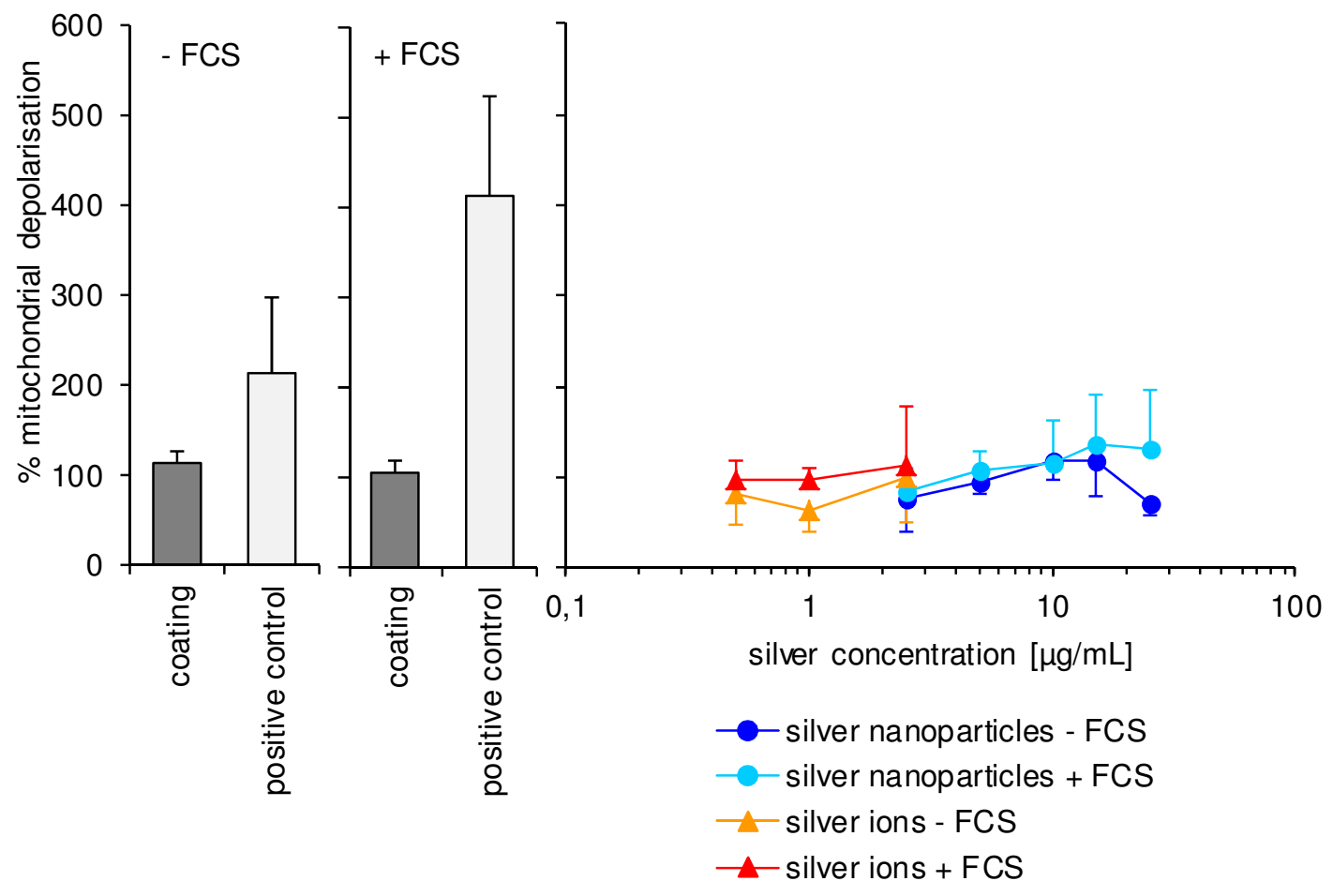

Figure S 8: Measurements of the mitochondrial depolarization in differentiated Caco-2 cells after incubation with surfactant coated silver nanoparticles or silver ions for 24 h. 10,000 Caco-2 cells per well were seeded into 96 well plates, differentiated for 21 days and incubated. Positive control was $2.5 \mu \mathrm{M}$ staurosporine. Measurements were done by JC-10 assay. Medium control was set to $100 \%$. The experiment was reproduced tree times.

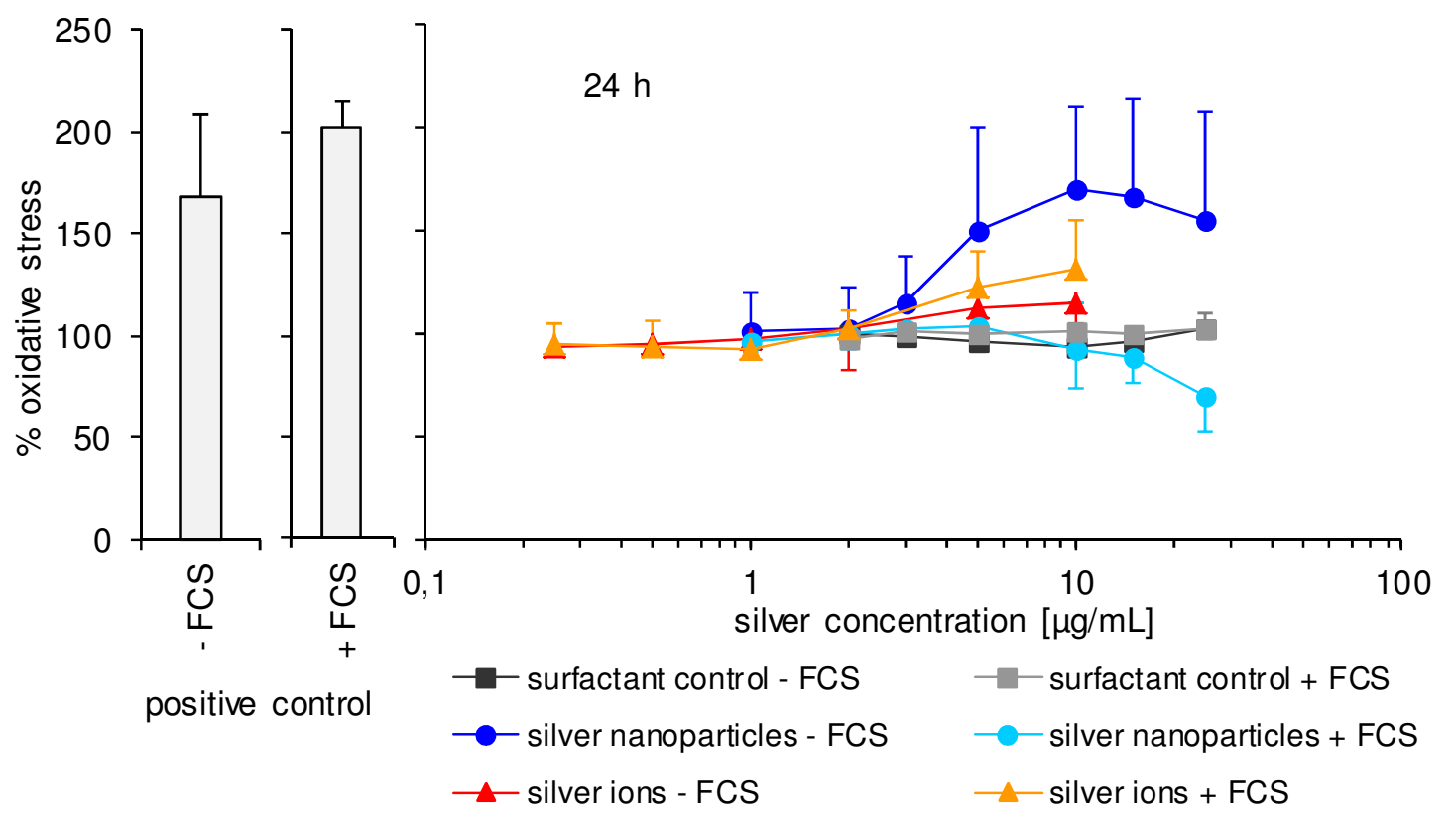

Figure S 9: Oxidative stress measurements in differentiated Caco-2 cells after $24 \mathrm{~h}$ of incubation with surfactant coated silver nanoparticles and silver ions. 10,000 Caco-2 cells per well were seeded into 96 well plates, differentiated for 21 days and incubated. Positive control was 100 $\mu \mathrm{g} / \mathrm{mL}$ iron ions $\left(\mathrm{FeSO}_{4}\right)$. Prior to incubation, cells were treated with 2,7\%dichlorodihydrofluorescein diacetate in serum free media for $1 \mathrm{~h}$ and washed with PBS. Results are expressed as $\%$ oxidative stress and medium control was set to $100 \%$. The experiment was reproduced four times. 

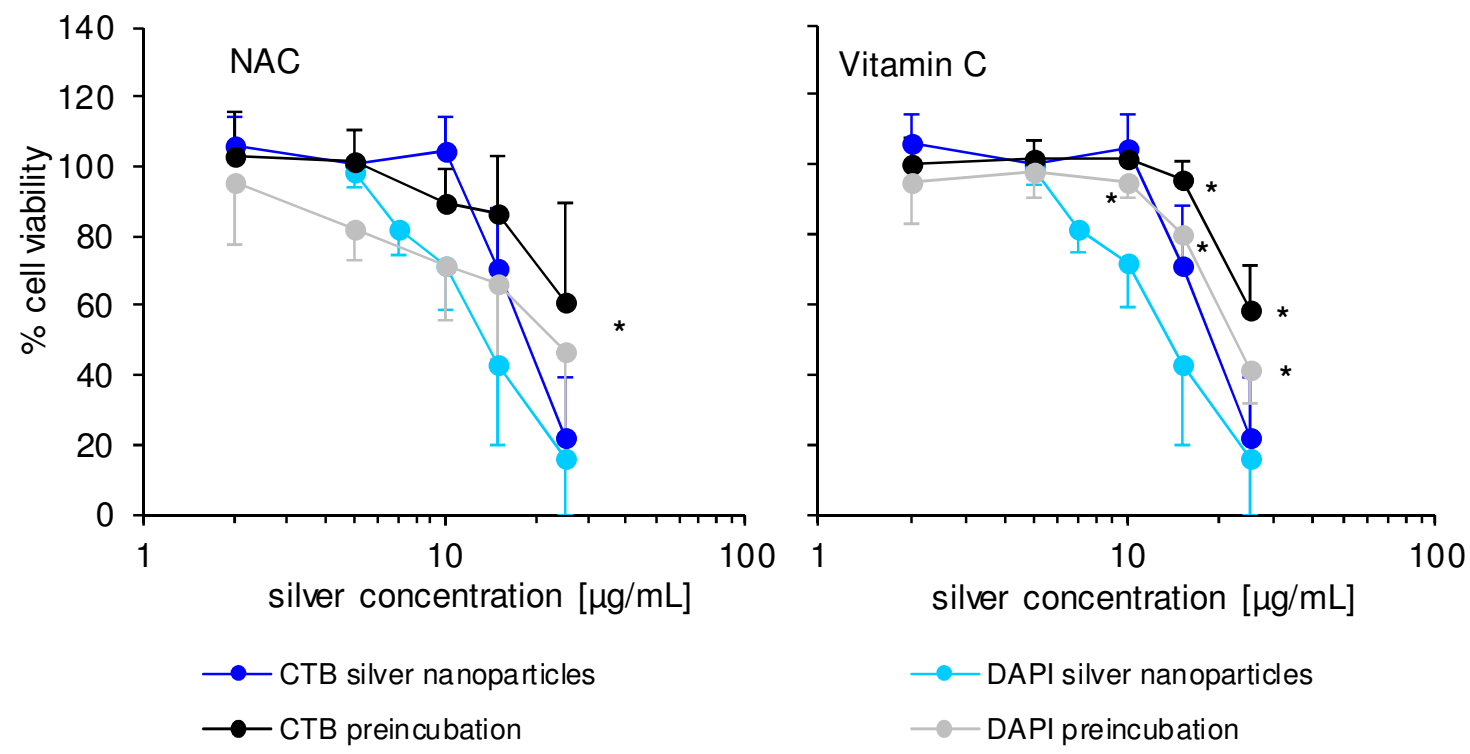

Figure S 10: Results of preincubation with the antioxidants $\mathrm{N}$-acetylcysteine and vitamin $\mathrm{C}$ and cell viability measurements with CTB assays and DAPI staining of proliferating Caco-2 cells after incubation with surfactant control, surfactant coated silver nanoparticles and silver ion in serum free media. 10,000 Caco-2 cells per well were seeded into 96 well plates and cultivated for $24 \mathrm{~h}$. They were preincubated with antioxidants for $1 \mathrm{~h}$ and incubated in $100 \mu \mathrm{L}$ for $24 \mathrm{~h}$. Medium control was set to $100 \%$. The experiment was reproduced three times. ${ }^{*}$ marks significant differences compared to preincubated cells (student's t test $\mathrm{p} \leq 0.05$ ).

Table S 1: Comparative list of gene expression results measured by real-time RT-PCR analysis. Caco-2 cells were differentiated for 21 days and incubated with surfactant coated silver nanoparticles for $24 \mathrm{~h}$ in serum free and serum containing cell culture medium. The color red indicates an upregulation and green a downregulation, as compared to the medium control

\begin{tabular}{|c|c|c|c|c|c|}
\hline \multirow{4}{*}{$\begin{array}{c}\text { category } \\
\text { stress and } \\
\text { inflammation }\end{array}$} & gene & $\begin{array}{l}+ \text { FCS } \\
\text { silver nan } \\
5 \mu \mathrm{g} / \mathrm{mL}\end{array}$ & $\begin{array}{l}\text { oparticles } \\
10 \mu \mathrm{g} / \mathrm{mL}\end{array}$ & $\begin{array}{l}\text { - FCS } \\
\text { silver nar } \\
5 \mu \mathrm{g} / \mathrm{mL}\end{array}$ & $\begin{array}{l}\text { oparticles } \\
10 \mu \mathrm{g} / \mathrm{mL}\end{array}$ \\
\hline & ALB & -2.1 & & & -2.9 \\
\hline & HSPA6 & 238.0 & 358.2 & 23.5 & 466.4 \\
\hline & HMOX1 & 51.3 & 105.2 & 4.8 & 77.2 \\
\hline cellular & FN1 & & & & \\
\hline morphology & OCLN & -2.1 & -3.1 & & \\
\hline and cellular & CLDN3 & & -2.2 & & \\
\hline movement & TJP3 & & -2.4 & & \\
\hline & ACTB & 2.2 & 2.9 & & 2.1 \\
\hline & FOS & 4.0 & 8.7 & & 6.3 \\
\hline & ITGA2 & 3.1 & 3.3 & & \\
\hline & TUBB3 & 29.8 & 44.1 & 2.6 & 20.0 \\
\hline calciu & CXCR4 & 2.4 & 4.8 & 2.4 & 5.1 \\
\hline homeostasis & CAMK2D & & -2.5 & & \\
\hline
\end{tabular}


Table S 2: Comparative list of gene expression results measured by microarray and real time RT PCR analysis. Caco-2 cells were differentiated in $75 \mathrm{~cm}^{2}$ cell culture flask for 21 days and incubated with surfactant coated silver nanoparticles or silver ions for $24 \mathrm{~h}$ in serum free medium. The microarray and the PCR analysis no. (1) were performed with the same mRNA samples, whereas the PCR analysis no. (2) was done with samples of a biological replicate. The color red indicates an upregulation and green a downregulation, as compared to the medium control (fold change $\leq 1,4$ and Student's t-Test $\mathrm{p}<0.05$ ).

\begin{tabular}{|c|c|c|c|c|c|c|c|c|c|c|c|c|c|c|c|}
\hline & 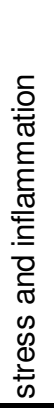 & 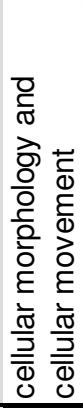 & 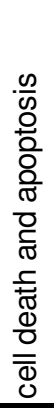 & 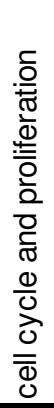 & 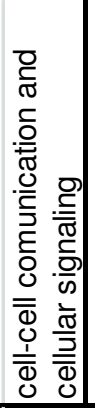 & $\begin{array}{l}\text { ते } \\
\frac{2}{\frac{2}{\pi}} \\
\frac{0}{0} \\
\frac{0}{\varepsilon}\end{array}$ & 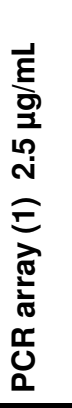 & 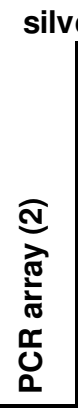 & 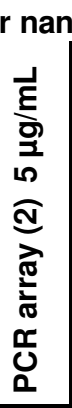 & 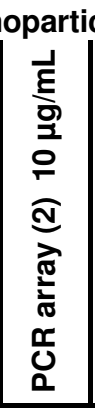 & 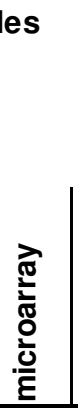 & 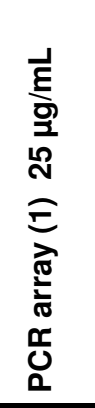 & 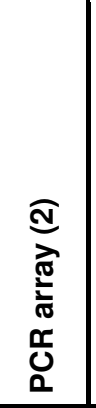 & silver & 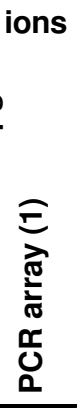 \\
\hline ACTB & $x$ & $X$ & $\mathrm{X}$ & $\mathrm{X}$ & $\mathrm{X}$ & & & & 3.7 & & & & 5.0 & & \\
\hline ACTG2 & & $X$ & & & & & & & & & 2.7 & 2.1 & -2.1 & & \\
\hline ACTN2 & & $X$ & & & $X$ & & & & & 145.0 & 3.0 & 156.3 & 60.9 & & \\
\hline ACTN4 & $X$ & $X$ & $X$ & $X$ & & & & & 11.7 & & 2.1 & \begin{tabular}{|r|}
4.4 \\
\end{tabular} & 15.5 & & \\
\hline ALB & $X$ & $X$ & $X$ & $X$ & $X$ & & & & & & -4.7 & -4.7 & & -1.5 & \\
\hline ASAP1 & & $\mathrm{X}$ & & & $\mathrm{X}$ & & & & 9.9 & & 1.8 & 5.9 & 14.2 & & \\
\hline ATF3 & $X$ & $X$ & $X$ & $X$ & $X$ & & & 1.9 & & 13.3 & 3.4 & 3.5 & 2.0 & & \\
\hline B2M & $X$ & $X$ & $X$ & $X$ & $X$ & & & 1.6 & & 1.7 & -1.6 & -5.8 & & & \\
\hline BAG3 & $X$ & $X$ & $\bar{X}$ & & & & & & 1.8 & 16.7 & 3.9 & 7.8 & 7.3 & & \\
\hline BCL10 & & $X$ & $\mathrm{X}$ & $X$ & $X$ & & & & -2.7 & 1.0 & -2.8 & & -2.5 & & \\
\hline BCL2L11 & $X$ & $X$ & $X$ & $\mathrm{X}$ & $\mathrm{X}$ & & & & -2.8 & & -2.6 & -3.2 & & -1.6 & \\
\hline BDNF & $X$ & $X$ & $\mathrm{X}$ & $X$ & $X$ & & & & 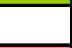 & & 2.3 & 6.5 & 3.3 & & \\
\hline BRAF & & $x$ & $x$ & $X$ & $X$ & & & & 2.4 & & -4.4 & & & & \\
\hline CAPN10 & & & $X$ & & & & & & 17.8 & & -2.1 & 4.0 & 11.9 & & \\
\hline CAPN3 & & $X$ & $X$ & & & & & & 6.0 & & -2.2 & & 3.1 & & \\
\hline CAT & $X$ & $x$ & $x$ & $X$ & $X$ & & & & 4.8 & & -3.0 & & 1.6 & & \\
\hline CCT5 & $X$ & & $X$ & $X$ & & & & & & & 2.3 & & & & \\
\hline CDKN1A & $x$ & $X$ & $x$ & $\mathrm{X}$ & $X$ & & & & & 7.1 & 2.0 & 2.3 & & & \\
\hline COL5A2 & & & & & & & & & 2.6 & & -5.1 & & & & \\
\hline CTNND1 & & $X$ & & $X$ & $X$ & & & & 10.6 & & -2.0 & 2.2 & 9.7 & & \\
\hline CTTN & $X$ & $X$ & $X$ & $X$ & & & & & 44.5 & & -1.3 & 8.7 & 49.2 & & \\
\hline CUX1 & & $X$ & $X$ & $X$ & & 1.5 & & & 4.7 & & & 2.7 & 4.9 & & \\
\hline CYFIP2 & & & $x$ & & & & 1.9 & & & & -2.6 & & & & \\
\hline CYR61 & $X$ & $X$ & $x$ & $X$ & $X$ & & & & 14.0 & & 3.5 & 16.3 & 62.8 & & \\
\hline DAPK1 & & & $X$ & $X$ & & & & & -2.1 & -5.2 & -2.1 & -3.0 & -5.3 & & \\
\hline DIDO1 & & $X$ & $X$ & $X$ & & 1.6 & & & 11.9 & & & 2.5 & 9.4 & & \\
\hline DNAJB6 & $X$ & $X$ & $X$ & $X$ & & & & & 4.3 & 11.6 & 2.6 & 5.8 & 7.1 & & \\
\hline DOCK1 & & $X$ & $X$ & & & & & & 2.8 & & -2.0 & 1.7 & 1.6 & & \\
\hline DUSP1 & $X$ & $X$ & $X$ & $X$ & $X$ & & & & 6.4 & 142.7 & 3.7 & 16.4 & \begin{tabular}{|l|}
66.1 \\
\end{tabular} & & \\
\hline DUSP2 & $\mathrm{X}$ & & $X$ & $X$ & & & & 93.3 & 74.4 & 619.0 & 3.9 & 11.4 & 403.8 & & \\
\hline DUSP4 & & & $X$ & $X$ & & & & & 13.1 & & 3.7 & 23.1 & \begin{tabular}{|l|}
69.5 \\
\end{tabular} & & \\
\hline DUSP6 & & $X$ & $X$ & $X$ & & & & & 12.4 & & 4.7 & 14.8 & 31.6 & & \\
\hline DUSP9 & & & $\mathrm{X}$ & $X$ & & & & & 2.3 & & -2.9 & -5.1 & & & \\
\hline EGR1 & & $X$ & $X$ & $X$ & $X$ & & & & & & 4.4 & 4.9 & & & \\
\hline EPHX2 & $X$ & & $X$ & $X$ & & & & & 2.7 & & -4.3 & 11.1 & & & \\
\hline ETS1 & $X$ & $X$ & $X$ & $X$ & $X$ & & & & & & 2.7 & 31.3 & & & \\
\hline EXT1 & & & & & & 1.6 & & & -2.5 & & 2.0 & & -2.6 & & \\
\hline FAM129A & $X$ & & & & & 1.7 & & & 8.5 & & 2.2 & 9.6 & 6.2 & & \\
\hline FN1 & $X$ & $X$ & $X$ & $X$ & $X$ & & & & 6.0 & 2.3 & 2.0 & 3.0 & \begin{tabular}{|l|}
9.1 \\
\end{tabular} & & \\
\hline FOS & $X$ & $X$ & $\mathrm{X}$ & $X$ & $X$ & & & & 12.7 & & 6.0 & 21.9 & \begin{tabular}{|l|}
118.1 \\
\end{tabular} & & \\
\hline FOSB & $X$ & & $X$ & $X$ & & & & & 8.7 & & 2.6 & 23.5 & \begin{tabular}{|l|}
27.6 \\
\end{tabular} & & \\
\hline FOSL1 & & $X$ & $X$ & $X$ & $X$ & & & & 3.4 & 433.4 & 7.8 & 99.8 & 106.8 & & \\
\hline
\end{tabular}




\begin{tabular}{|c|c|c|c|c|c|c|c|c|c|c|c|c|c|c|c|}
\hline & 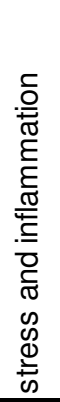 & 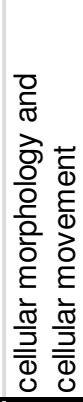 & 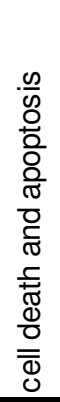 & 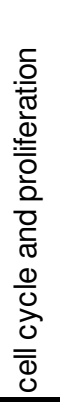 & 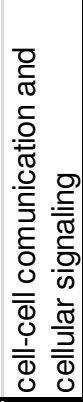 & 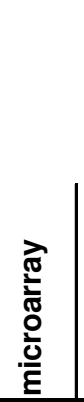 & 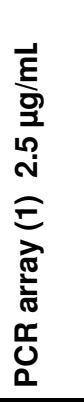 & 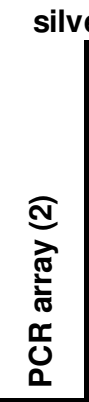 & 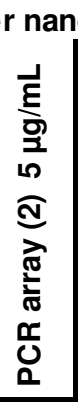 & 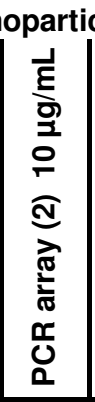 & 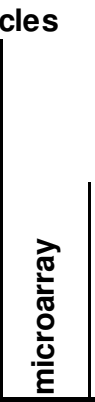 & 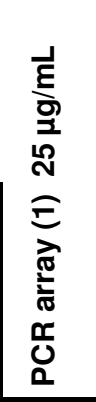 & 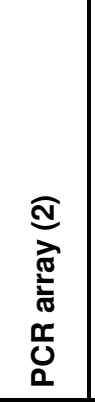 & silver & \begin{tabular}{l} 
ions \\
\multirow{E}{E}{} \\
$\frac{\pi}{\sqrt{2}}$ \\
$\frac{\pi}{\pi}$ \\
$\frac{\pi}{0}$ \\
$\square$
\end{tabular} \\
\hline GADD45B & $x$ & & $x$ & $X$ & & & & & -2.2 & 7.7 & 3.6 & 4.6 & 2.4 & & \\
\hline GSTA1 & $X$ & & $X$ & & & & & & & & -2.4 & & & & \\
\hline GSTA4 & $X$ & & & & & & & & & & -2.0 & & \begin{tabular}{|r|}
-2.2 \\
\end{tabular} & & \\
\hline HMOX1 & $X$ & $X$ & $X$ & $X$ & $X$ & & & 84.2 & 22.0 & 649.1 & 17.2 & 45.7 & 277.9 & & \\
\hline HSPA1A & $X$ & $x$ & $x$ & $X$ & $x$ & & & 2.6 & & 18.6 & \begin{tabular}{|l|}
5.6 \\
\end{tabular} & \begin{tabular}{|l|}
20.7 \\
\end{tabular} & \begin{tabular}{|r|}
6.3 \\
\end{tabular} & & \\
\hline HSPA6 & $\mathrm{X}$ & & & & & & & 14.0 & & 240.3 & \begin{tabular}{|l|}
106.8 \\
\end{tabular} & 296.0 & 42.7 & & \\
\hline HSPH1 & & & $X$ & & $X$ & & & & -2.0 & 7.6 & 3.3 & 5.2 & 2.2 & & \\
\hline IGFBP7 & $X$ & $X$ & & $X$ & $X$ & & & & & & -1.9 & & & & \\
\hline ITGA2 & & $x$ & $X$ & $x$ & $x$ & & & & 14.6 & & 2.9 & 15.3 & 47.7 & & \\
\hline JMJD1C & & & & & & & & & 4.6 & & & 2.5 & 5.6 & & \\
\hline JUN & $X$ & $X$ & $X$ & $\mathrm{X}$ & $x$ & & & & 49.2 & & 4.2 & 31.3 & 265.9 & & \\
\hline MAP1A & & & & & & & & 1.9 & & 8.9 & 3.2 & 4.1 & \begin{tabular}{|r|}
3.4 \\
\end{tabular} & & \\
\hline MCL1 & $X$ & $X$ & $X$ & $X$ & & & & & & 1.3 & 3.0 & & & & \\
\hline MMP1 & $X$ & $X$ & $X$ & $X$ & $x$ & & & & & & 7.6 & 11.3 & 6.4 & & \\
\hline MMP10 & $X$ & $X$ & & $X$ & & & & & 2.7 & & 5.3 & 17.5 & 17.7 & & \\
\hline MMP11 & & $X$ & $X$ & $X$ & & & & & & & -2.0 & -5.7 & & & \\
\hline MMP7 & & $X$ & $X$ & $x$ & $X$ & & & & & 12.0 & 2.8 & 8.4 & 2.0 & & \\
\hline MPHOSPH8 & & & & & & 0.4 & 1.5 & & 5.1 & 2.2 & -1.2 & 4.2 & & & \\
\hline MT1F & $X$ & $X$ & $X$ & & & -1.9 & & 16.1 & & \begin{tabular}{|l|}
53.2 \\
\end{tabular} & 12.2 & \begin{tabular}{|l|}
18.3 \\
\end{tabular} & \begin{tabular}{|l|}
19.6 \\
\end{tabular} & & \\
\hline MT1G & $X$ & & & & & -1.7 & & 29.9 & & 299.9 & 11.9 & 191.5 & 248.5 & & \\
\hline MT1H & $\mathrm{X}$ & $X$ & $X$ & $X$ & & -1.8 & -2.4 & \begin{tabular}{|l|}
30.0 \\
\end{tabular} & & 148.6 & 14.2 & 96.6 & \begin{tabular}{|l|}
88.7 \\
\end{tabular} & & \\
\hline MT1M & $x$ & & & & & & & \begin{tabular}{|l|}
110.7 \\
\end{tabular} & & 536.0 & 43.6 & 523.4 & 209.3 & & \\
\hline MT1X & $X$ & & $X$ & $X$ & & -2.3 & -2.2 & \begin{tabular}{|l|}
83.0 \\
\end{tabular} & & 414.0 & 9.5 & 51.6 & \begin{tabular}{|l|}
273.2 \\
\end{tabular} & -1.6 & -2.8 \\
\hline MT2A & $X$ & $X$ & $X$ & $X$ & & -2.1 & -2.3 & 8.0 & & 36.5 & 7.7 & 22.5 & \begin{tabular}{|l|}
17.8 \\
\end{tabular} & & \\
\hline MYL12A & $X$ & & & & & & & & & 1.8 & & & & & \\
\hline MYLK & $X$ & $X$ & $X$ & $X$ & & & & & -2.3 & & -2.3 & & & & \\
\hline PAK1 & & $X$ & $X$ & $X$ & $X$ & & & & & & -2.1 & & -2.2 & & \\
\hline PPARA & $X$ & $X$ & $X$ & $X$ & $X$ & & & & 6.4 & 3.7 & -1.9 & & 2.6 & -1.5 & \\
\hline PPARG & $X$ & $X$ & $X$ & $X$ & $x$ & & & & & & -2.1 & & & & \\
\hline PPP1R14A & & & & & & & & & & & -2.9 & & & & \\
\hline PPP1R15A & & $X$ & $X$ & $X$ & $X$ & & & & 26.8 & & 3.0 & 21.5 & 125.1 & & \\
\hline PPP1R16A & & & & & & & & & 14.0 & & -2.8 & 2.0 & \begin{tabular}{|l|}
10.3 \\
\end{tabular} & & \\
\hline PPP2R5C & & $X$ & $x$ & $x$ & & & & & 1.5 & & -2.5 & & & & \\
\hline PRDX2 & $X$ & $x$ & $x$ & $x$ & & & & 23.1 & 24.7 & 18.3 & 2.0 & & 16.7 & & \\
\hline PTK2 & & $x$ & $\mathrm{X}$ & $\mathrm{X}$ & $X$ & & & & 5.4 & & -3.3 & 2.8 & 4.6 & & \\
\hline RXRA & $X$ & $x$ & $X$ & $X$ & $X$ & & & & & & -3.0 & -2.4 & & & \\
\hline SOS1 & & $X$ & & $X$ & & & & & 3.2 & 2.3 & 2.0 & 2.5 & 1.8 & & \\
\hline SPARC & $X$ & $x$ & $X$ & $X$ & $X$ & & & 4.6 & 5.5 & 2.9 & -2.2 & & \begin{tabular}{|l|}
4.9 \\
\end{tabular} & & \\
\hline SRXN1 & $X$ & $x$ & $X$ & & & & & & 24.3 & & 6.0 & 42.7 & 106.6 & & \\
\hline TCF7L2 & $X$ & $X$ & $X$ & $X$ & & & & & & & 1.5 & & & & \\
\hline TGFBI & & $X$ & $X$ & $X$ & $X$ & & & & 2.3 & & -2.5 & & & & \\
\hline THBS1 & $x$ & $x$ & $x$ & $x$ & $x$ & & & & 2.7 & 5.9 & 2.2 & 8.0 & \begin{tabular}{|r|}
3.3 \\
\end{tabular} & & \\
\hline TUBB3 & $\mathrm{X}$ & $\mathrm{X}$ & $X$ & $\mathrm{X}$ & & & & & 41.6 & & 2.2 & 79.0 & 349.7 & & \\
\hline TUBGCP3 & & & & & & & & & 6.5 & 8.5 & -1.2 & 5.5 & \begin{tabular}{|l|}
5.4 \\
\end{tabular} & & \\
\hline TXNRD1 & $X$ & & $X$ & $X$ & $X$ & & & & & 4.7 & 3.5 & 3.6 & & & \\
\hline $\mathrm{VCL}$ & $X$ & $X$ & $X$ & $X$ & $X$ & & & & & 2.5 & 2.3 & 2.3 & & & \\
\hline$\overline{Z Y X}$ & $X$ & $X$ & $X$ & $X$ & $x$ & & & & 7.0 & & & 8.4 & 14.8 & & \\
\hline
\end{tabular}




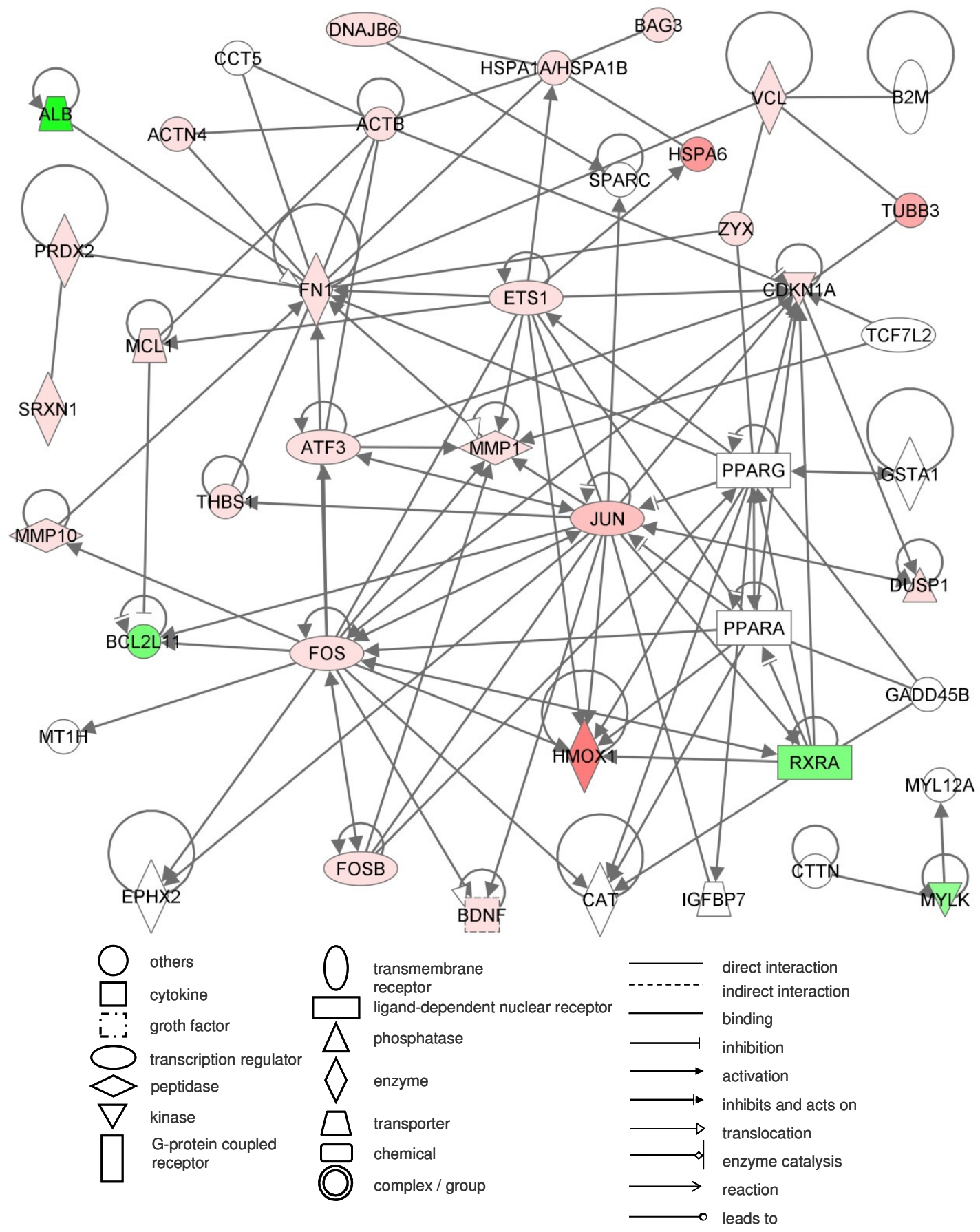

Figure S 11: Network of genes that belong to the group "stress and inflammation" and were analyzed in the microarray as well as in the real time RT-PCR analysis. The network was created by Ingenuity Pathway Analysis (IPA) software using the PCR verified date. The color red indicates an upregulation and green a downregulation, as compared to the medium control. 


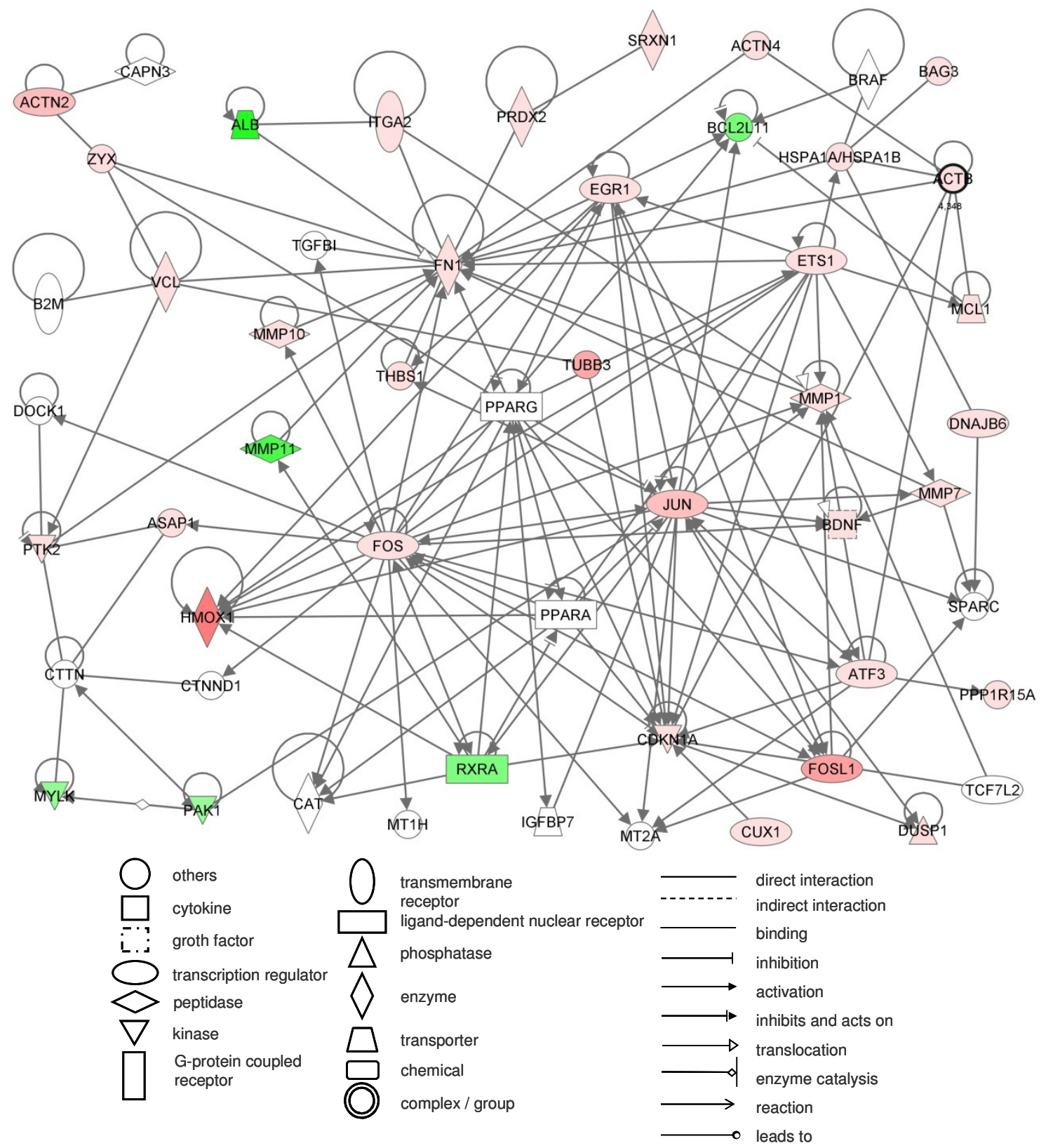

Figure S 12: Network of genes that belong to the group "cellular morphology and cellular movement" and were analyzed in the microarray as well as in the real time RT-PCR analysis. The network was created by Ingenuity Pathway Analysis (IPA) software using the PCR verified date. The color red indicates an upregulation and green a downregulation, as compared to the medium control. 


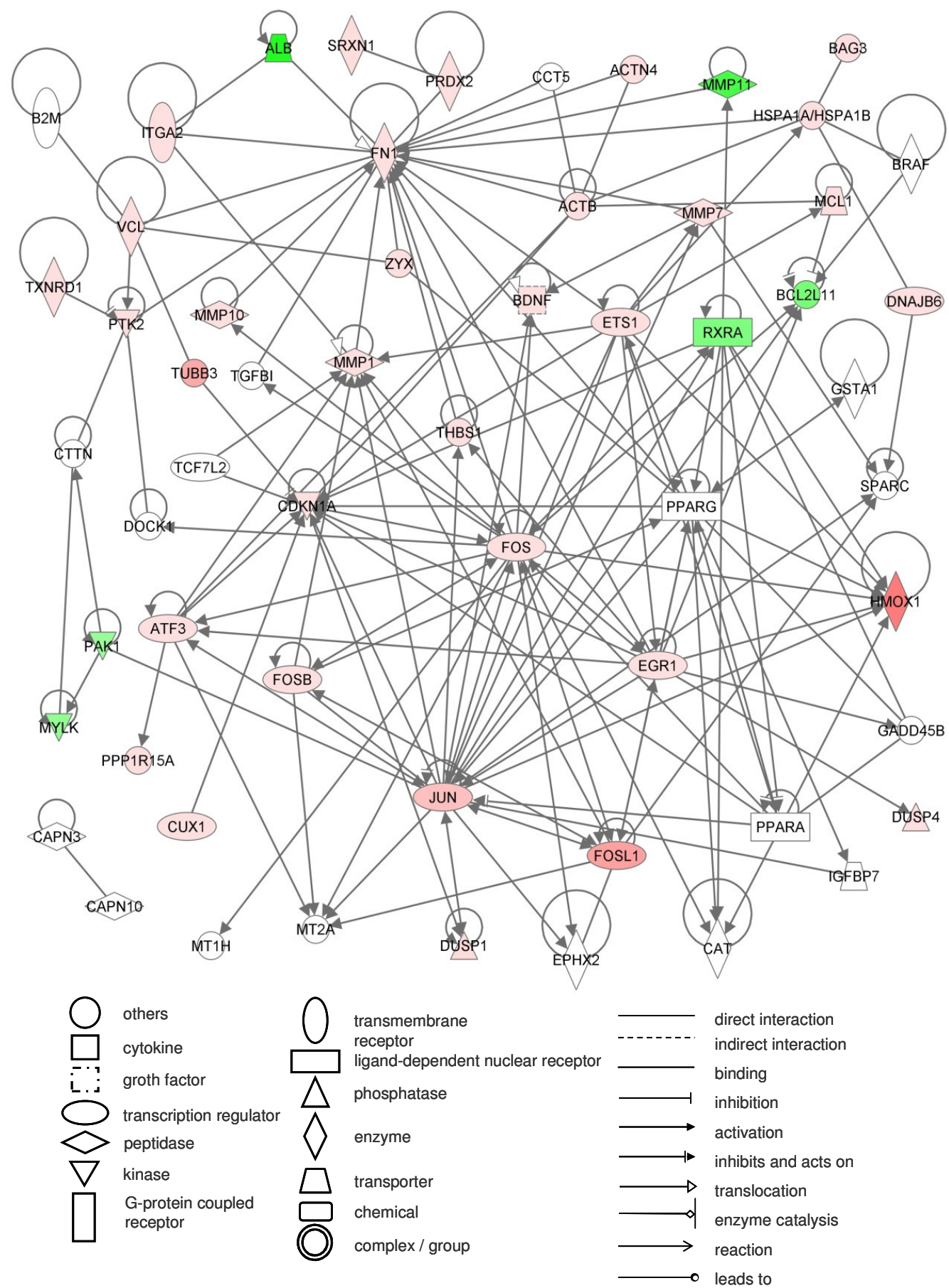

Figure S 13: Network of genes that belong to the group "cell death and apoptosis" and were analyzed in the microarray as well as in the real time RT-PCR analysis. The network was created by Ingenuity Pathway Analysis (IPA) software using the PCR verified date. The color red indicates an upregulation and green a downregulation, as compared to the medium control. 


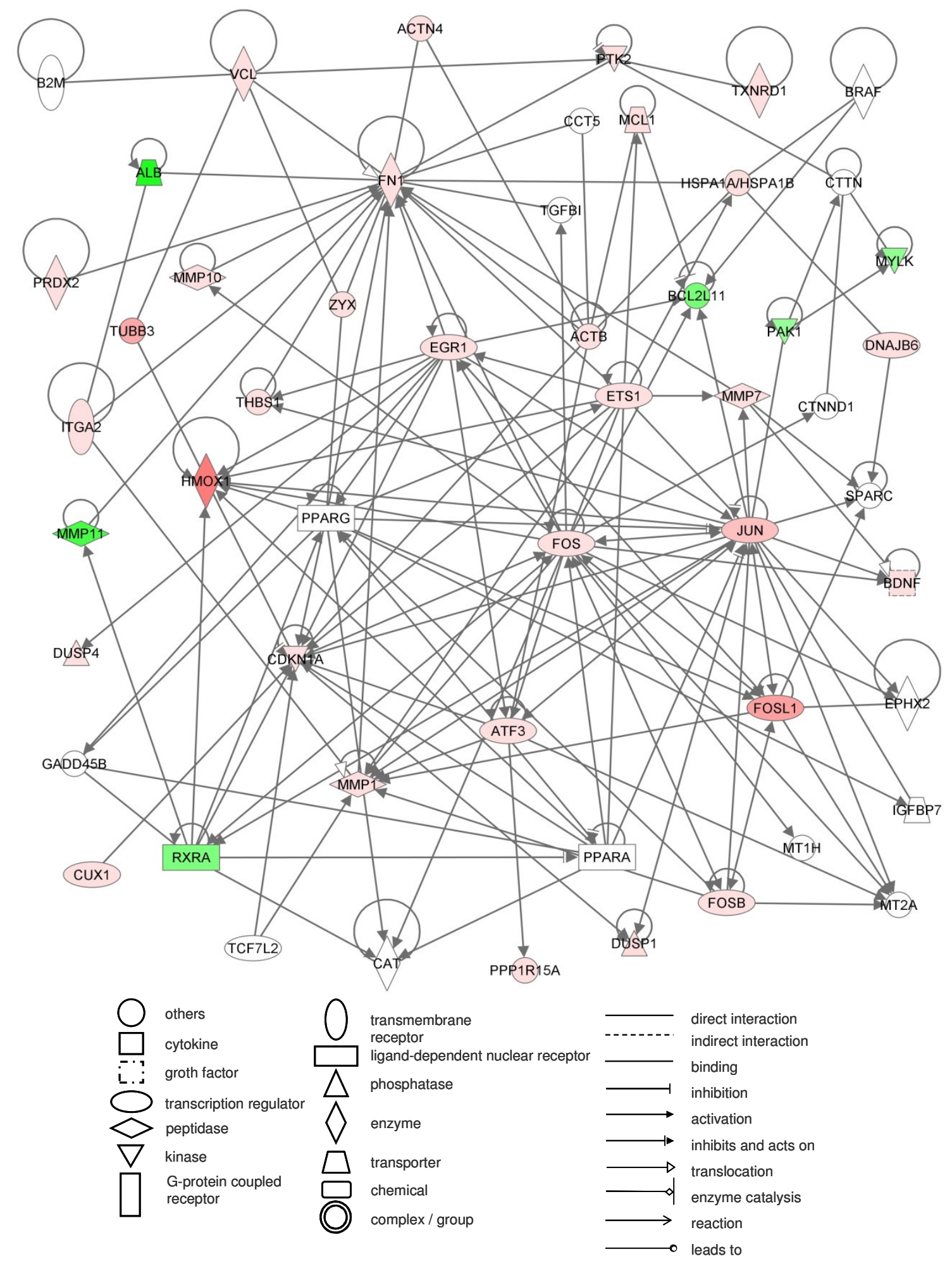

Figure S 14: Network of genes that belong to the group "cell cycle and proliferation" and were analyzed in the microarray as well as in the real time RT-PCR analysis. The network was created by Ingenuity Pathway Analysis (IPA) software using the PCR verified date. The color red indicates an upregulation and green a downregulation, as compared to the medium control. 


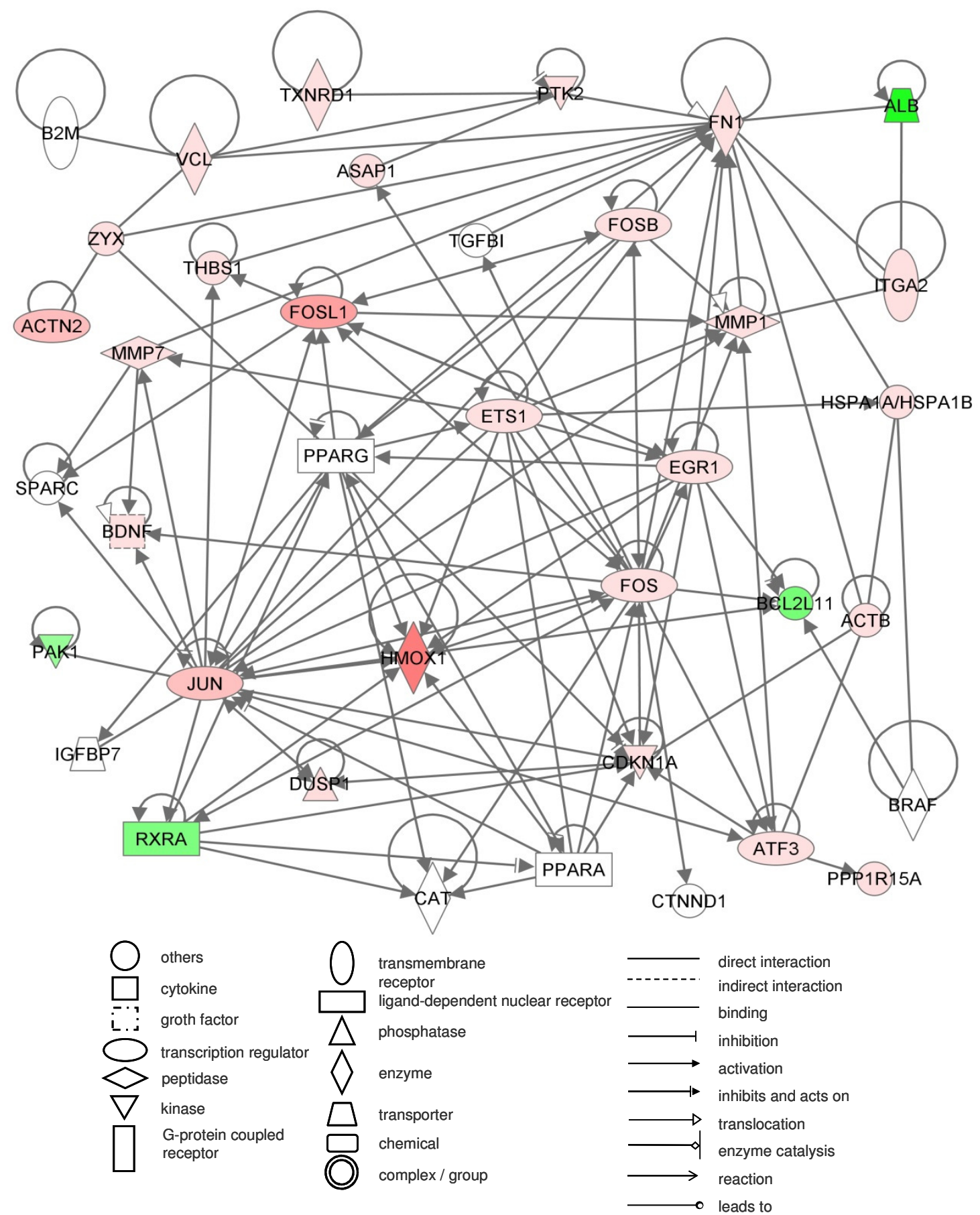

Figure S 15: Network of genes that belong to the group "cell-cell communication and cellular signaling" and were analyzed in the microarray as well as in the real time RT-PCR analysis. The network was created by Ingenuity Pathway Analysis (IPA) software using the PCR verified date. The color red indicates an upregulation and green a downregulation, as compared to the medium control. 